\title{
North-South dialogues: reflecting on working transnationally with young men, masculinities and gender justice.
}

\author{
Tamara Shefer, Jeff Hearn and Kopano Ratele
}

\begin{abstract}
Dialoguing across national borders and specifically global margins has increasingly been viewed as a way to enhance critical and feminist studies and engagement with men and masculinities. This article draws on narratives generated by a group of researchers in South Africa and Finland who have been engaged in a transnational research project that included a strong focus on young men, masculinities and gender and sexual justice. The piece provides an account of the nuanced and complex experiences and dynamics involved in transnational research collaboration, particularly within the framework on historical and continued inequalities between the global North and South. While obvious benefits are raised, this experience also foregrounds a range of challenges and constraints involved in transnational research collaboration within this field and possibly many others. Key learnings gleaned from this analysis of reported experiences and thoughts include the importance of careful, considered and critical reflexivity at all moments and at all levels, both in interpersonal and intergroup relations, as well as in public representation of collaborative work.
\end{abstract}

\section{Introduction}

Critical and feminist research on men and masculinities has been stimulated by several major disciplinary traditions, but it has also been notable for the valuation of transdisciplinary dialogue. Many crossovers can be identified, between cultural studies, history, humanities, political science, psychology and psychoanalysis, science and technology studies, social policy, sociology and so on. In keeping with its position as a sub-field of Feminist Studies/Gender Studies/Women's Studies, these focused studies on men and masculinities have been strongly multidisciplinary, sometimes transdisciplinary, possibly on occasions even post-disciplinary. The task has been to develop critical, (pro) feminist, anti-oppressive, theoretically informed and empirically grounded studies, not to see whether they fit the canon of one of other of the established disciplines.

The record of critical and feminist research on men and masculinities in relation to geographical location and locationality is more mixed. The majority of such research on men and masculinities has had a local or national focus, in keeping with the so-called ethnographic moment (Connell, 2000). However, at the same time, there has been a long history, even if less visible, of acknowledging the value of transnational conversations about both global and local contexts of boys, men and masculinities (Connell, 1993; 
Hearn, 1996; Pease \& Pringle, 2002; Ratele, 2014). Indeed, texts which share and reflect on theoretical and programmatic work across international contexts in this area have proliferated in recent years (for example, Carabí \& Armengol, 2014; Cornwall, Edström, \& Greig, 2011; Gelfer, 2013; Hearn, Blagojević, \& Harrison, 2013; Ruspini, Hearn, Pease, \& Pringle, 2011; van der Gaag, 2014).

Observers have perceived a rise in studies on men going beyond 'methodological nationalism' and concentrations on the nation-state, as the taken-for-granted context (Hearn, 2015b). Further, the benefits of comparative, international and transnational studies across different national contexts and/or transnational teams of researchers working together on a collective project has been increasingly noted and evident in a growing scholarship within different disciplinary areas (see, for example, Airhihenbuwa et al., 2011; Hearn, 2014, 2015a; Reddy, Meyer, Shefer, \& Meyiwa, 2014). Dialoguing across national borders, and specifically global North-South centres and margins, is a way to enhance critical and feminist studies and engagement with men and masculinities. Within this terrain of critical work on men and masculinities, a recent collaborative project between Swedish and South African researchers on the use of the concept hegemonic masculinity provides a good example of the benefits of such practices (Hearn \& Morrell, 2012; Hearn et al., 2012; Morrell, Jewkes, \& Lindegger, 2012). This project yielded valuable insights into similarities and differences in the way in which scholarship on masculinities has contributed to challenging gender inequalities in these different contexts and provided valuable conclusions relevant in each national context as well as to the larger scholarship. Another cross-border project on a similar terrain is the 'The Social Problem and Societal Problematisation of Men and Masculinities' collaborative. The Project initially included 10 countries, supplemented later by 3 more, including in all 5 post-socialist societies, Czech Republic, Estonia, Latvia, Poland and the Russian Federation. That project examined the state of knowledge on men and masculinities through academic research, statistical sources, policy development and media representations, and led to books and articles, some comparative (Pringle et al., 2006/2013), some more synthesising (Hearn \& Pringle, with members of Critical Research on Men in Europe, 2006). However, while international funding arrangements and instruments are increasingly important in providing the frameworks for much research, including research directed at gender transformation, across different national contexts and particularly for global Northern and Southern dialogues, there has been little reflection on the dynamics of such projects.

This article draws on reflections from one such transnational study, which forms the backdrop of this special edition. ${ }^{1}$ While some of the context of the project has been outlined in the editorial, a number of key contextual aspects are noteworthy for locating these reflections. The three-year bilateral project, funded through the Academy of Finland and South African National Research Foundation, brought together South African and Finnish researchers and activists from four different universities and one nongovernmental organisation (NGO)/state institution in South Africa and one university in Finland. Most of the researchers on the team had a long history of working on gender both in academic and civil society contexts. Given the context of the funding call that invited projects on children and youth (Academy of Finland, 2012), these researchers and activists came together to conduct a transnational dialogue on young people engaging in change. Although the topic was formulated to be fittingly relatively

\section{https://repository.uwc.ac.za/}


broad, the particular expertise of the researchers and activists involved meant that much of the focus was on gender, sexuality and intersections with other power inequalities, notably class and race through postcolonial feminist and critical masculinities lenses.

The group presented its work across a wide range of international contexts, both within South Africa and Finland, and also at two international conferences, one of them an international masculinities conference, 'Emerging ideas in masculinity research Masculinity studies in the North', held in Reykjavik, Iceland, in 2014, and the other the national joint 'Gender Studies and Cultural Studies Conference', held at the University of Lapland, Rovaniemi, Finland, in 2013. Among other events, in South Africa the project team organised a symposium, a public lecture and teach-in in 2013 and 2014. Over the last two and a half years of working together, we have not only generated scholarship related to the focus of the project but have gained much in thinking about how we have worked together, the opportunities and the constraints of and for such transnational collegiality.

Our discussion of the experiences of researchers on this project is based on an anonymous reflexive exercise. The entire team, a total of 11 people, 3 based in Finland, 8 in South Africa, including 7 based at academic institutions, 1 in an NGO/state institution, and $3 \mathrm{PhD}$ candidates registered at universities in South Africa, were invited to reflect on three questions related to working together on the project. Those who responded, 9 out of 11, submitted written responses and gave consent for their narratives to be analysed. As it will become obvious, the respondents reveal critical, self-reflexive stances towards working in a North-South international/transnational project, although they do invite further thorough critical interrogation. Even then, the principal burden of this article is less on probing the responses and more on sharing reflections on the international/ transnational project.

The responses were collated by a researcher unrelated to the project, who ensured confidentiality and anonymity of the authors before submitting the responses to the guest editors of this edition. We present responses within the framing questions which focused on (1) the value of working transnationally, (2) the challenges and constraints of working transnationally and (3) 'lessons' for constructive, equitable working together transnationally. ${ }^{2}$ While we reflected on these three areas in terms of studying young men, masculinities and gender justice, many of the insights shared here could indeed be of significance in thinking about transnational projects focusing on other areas of research.

Gains, possibilities and value of working transnationally on young men, masculinities and gender justice Researchers on this team mostly felt that there is value in working and thinking across national contexts on young men, masculinities and gender issues in general. One clear benefit articulated relates to the value of a sharing of international 'intellectual resources' especially in global Southern contexts such as South Africa, generally located in more marginal spaces in the global academic community. This is seen to be especially valuable for emerging researchers who may benefit from working with international 'experts' who live in different parts of the world to oneself and yet whose scholarship is foundational as articulated by this narrator ${ }^{3}$ : 
Obvious gains further relate to accessing expertise and other resources in transnational contexts so to be able to work with feminist researchers whose work has been foundational on gender and men and masculinities is a privilege and can profoundly develop one's own thinking. Having access to such 'experts' and researchers and authors who have long been developing scholarship on men and masculinities is also very helpful for our postgraduate students and emerging authors who can draw on their work and be exposed directly to their work.

A related spin-off of was the acknowledgment that transnational collaboration may assist the development of personal authorship and career development, again especially valuable for emerging researchers and those in more marginal academic contexts of the global South:

Other gains have been linking with resources for getting one's work published and known - thus having a special edition such as this one is an opportunity for advancing our local work and for emerging and even established authors to publish in international forums.

Although the respondents acknowledged the value of working in an international/ transnational project, they tended to problematise some of the taken-for-granted views about the differences between the global North and South.

A strong thread in many of the responses was indeed the value of sharing research that takes place across global North and South contexts, given the historical differences and inequalities and levels of affluence and institutional development. At the same time, narrators such as the one below argue how such transnational sharing allows one to deepen one's understanding of one's own context and serves as a resource for alternative ways of thinking and responding to local challenges:

The gains/possibilities and value of working transnationally extends to all areas of research, including studies of men, masculinities and gender justice. Countries in the North and those in the South are on different levels in terms of their research priorities, what matters most at the time and progress in policy development. Thus, working transnationally provides the opportunities for countries to 'learn' from each other, the different strategies and methodologies that work in their various contexts and how these can be applied to other contexts and whether this would be productive practice. This does not necessarily mean that the North gets to 'feed' the South with information or vice versa. Instead, what this means is that the various parties or nationalities involved get to understand phenomena in the 'other' world, how things work and how issues of gender justice and studies of men and masculinities are approached and addressed within various contexts. This offers opportunities to learn and refine strategies used in approaching the relevant issues. It also provides alternative practices to research and ways of addressing and studying men and masculinities and issues of gender justice. (Author's emphasis)

Some respondents argued that critical masculinities research in South Africa and global Southern contexts have particular gains from such transnational projects, which will boost such work, given that such a focus is still marginal and under-researched. Yet as 
this narrator goes on to argue, global Southern countries such as South Africa may have particular strong contributions to make, given the particular historical and contemporary challenges:

Given that Men and Masculinity studies remain largely ignored in the developing world (albeit on the agenda in more developed contexts) there is a need to research Men and Masculinities in Africa (and in South Africa in particular) in order to understand what informs the endemic levels of gender violence; alternative ways in which masculinities are (and can be) performed; and ways to engage men on gender justice. South Africa is well placed to lead the work on boys and men, and should contribute to theorising contemporary (as well as historical) constructions of masculinities, taking into account local sociopolitical and cultural conditions which gives meaning to being men and women.

A key gain articulated by a number of narrators relates to the development of their own scholarship through deepened critical reflection. Respondents shared how the project has allowed for a different vantage point for reflecting on one's own research, in particular through seeing how those located outside of one's national context respond to our research, which allows for a clarification of one's own project in one's own context. Two examples of this kind of reflection are:

I increasingly understand how young men, masculinities and gender justice are theorized, researched and approached in different contexts. This has been useful. It becomes possible, as an illustration, in fact I start to more clearly see how one, and one's country, young people in one's country, masculinities, gender justice or injustice in one's country, are seen. I get to see what I am looking at is looked at by others from different place-identities, from other national vantage points. But in both cases, I start to see what is it others might not immediately see when we look at the same object. (Our emphasis)

I'm also learning that working transnationally can better - or maybe differently, or richly - inform how one sees young people, masculinities and gender justice men, and surely other topics, in other societies and cultures as well as how one see one's own society an culture. The input that I found informative in the SA-Finland project and visits to Finland was on Finland, Finnishness and social issues like racism.

One particular gain mentioned by a South African respondent in this respect is the way in which collaboration across different contexts can assist not only an appreciation of differences across contexts, but importantly also in challenging the sense of uniqueness that pervades much of South African thinking, given our particular experiences of apartheid:

The gains of working transnationally include learning lessons across contexts. It means thinking through local problems with a broader analytical lens but it also guards against the dangers of exceptionalism ${ }^{4}$ - thinking that your problems are only yours. In South Africa we tend to do this often in relation to our thinking about gender based violence and masculinities. Working transnationally enables one to challenge the notion of South Africa as consumed by a 'culture of violence'. (Our emphasis) 
A strong related thread is that the project reportedly stimulated greater self-reflexivity in one's own ongoing research for research team members, inspiring further challenging of our own beliefs and assumptions as articulated by two different respondents below:

Working transnationally is for me imperative, as that is the way the world works and is, and probably increasingly so. It is also very educational in shifting and challenging one's own, my own, assumptions, knowledge and approaches. In terms of working on young men, masculinities and gender justice specifically, this is not necessarily so different to these general arguments and reasons. (Our emphasis)

Collaboration makes it possible to question you own research focus, themes, and as angles or viewpoints of looking at your data and topics.

A key component of the gains with respect to self-reflexivity related for some to the acknowledgement or increased acknowledgement of the political nature of our research. This might be one of the most important 'findings' of this project and a general value of working transnationally on gender justice, men and masculinities: how our research, not only our activism, is always performing a political function. Research team members recognised that research may be appropriated and interpreted in particular ways, possibly serving to bolster or support problematic global discourses that relate to global inequalities and difference. One example for the South African researchers in particular is the realisation that presenting their research on gender, masculinity and violence in international contexts may unwittingly have served to bolster an 'othering' gaze on South Africa and global southern contexts in general as articulated by this narrator:

A primary advantage for me has been that working transnationally allows a different vantage point - when one presents one's work in a sense you see how others respond to it and you can see what we do, the impact of what we do, the way our work is represented, from another location. It is both worrying and enlightening particularly presenting southern work in northern contexts as you get a sense of how political your work is and the meanings, intended or unintended, that may be triggered by your work. This facilitates far more reflexivity and insight into the complexities of globalised constructions of gender and other intersectional identities. One example is around presenting work on men and masculinities in South Africa. I have become increasingly aware of how this fuels racist and classist 'othering' discourses setting up African men as the 'transnational problem'. I am now so cautious of how I speak, what images are constructed by our research, how in particular the north interprets our research and what they do with it that may inadvertently reproduce the very inequalities, stigmatization, othering and marginalization that we attempt to challenge.

Yet, others argue that the project may also serve more constructive political ends by destabilising historical power relations evident in knowledge production, for as evident throughout these responses and elaborated later is the 'danger' of reproducing Northern authority through such collaborations: 
Working transnationally also provides the opportunity for dialogue that de-constructs the notion of North-South 'top-down' approach where other nationalities believe they have the 'authority' to study other nationalities and almost constructing themselves as the status quo.

Respondents further highlighted the way in which transnational collaboration may deepen knowledge more generally, and allow for fresh insights into both local and global factors shaping gender inequality and contemporary patriarchies. Thus, this narrator points out the value of transnational project in facilitating appreciation of 'transnational forces' in understanding masculinities across multiple contexts:

However, I think one issue regarding young men, masculinities and gender justice is that it raises both similarities and differences, and also pushes one, me, to consider to what extent what appear as local conditions and problems encountered by and caused by young men are partly the result of transnational forces - political-economic, capitalist, neoliberal, imperialist, colonialist, as well as more particular changes around information and communication technologies, consumption, image and even fashion.

Another benefit mentioned by one narrator of transnational projects related to a more material gain, that of the facilitation of not only north-south collaboration but also indirectly more south-south collaboration that southern (and often also northern) partners do not always have the funds to support otherwise, at least in the broad fields that we work in. Thus, as this narrator points out, this project brought a range of local South African researchers together that was valuable in its own right:

Also of value as a feature of transnational projects whether focused on masculinities or gender or other topics is it allows for Southern partners to link with other Southern partners which is not always easily achieved as few funders support South-South collaboration.

This observation can be read in the context of the simple facts of geographical distance and dispersion when working within such a large country as South Africa. In addition, the way the South Africa-Finland project was organised enabled the South African partners to contribute towards bridging some of the divisions that characterise universities ${ }^{5}$ as well as the universities versus activism in that country.

Constraints and challenges of working transnationally A key challenge, articulated by a number of respondents, relates to continued differences in global Northern and global Southern contexts as well as the long-term, often unconscious assumptions that go with these. Thus, some argue that the material inequalities between countries, reflected also in the budgets of the project, ${ }^{6}$ together with associated attitudes of privilege and power, are evident in the relations in the teams and undermine such projects, even when they are themselves focused on a critical masculinities, a gender equality or a social justice project:

I think it is difficult to work across contexts which are shaped by hundreds of years of inequality across multiple axes and considering their continuities in the present. This is 
not necessarily a constraint related to working on young men, masculinities and gender justice in particular but perhaps is more profound since the work is so focused on deconstructing male privilege and power. Relationships are always potentially fraught and working on issues of power and masculinities does not unfortunately mitigate from research partners' own performances of hegemonic masculinities or taking power through different indices of power in their dealings with each other. Some of the power inequalities that are present are often beyond control but reflect and then further reproduce existing power inequalities are linked to resources - thus in a bilateral project you will usually find the Northern partner receives far more funding than the Southern partners and this may play out in problematic ways in the dynamics of working together.

Another narrator put it simply:

Of course there are always issues of power and money in all collaborations, but perhaps more so in so-called South-North collaborations. Respondents suggest that the dynamics of North-South collaboration may be particularly fraught in working in current postcolonial contexts given historical privileging and hegemonies of certain knowledges which play out in the team and shape certain practices and responses:

What also happens is that there is sensitivity on the part of partners in postcolonial contexts to the historical inequalities of working with the North and those in North are often so steeped in their own location, unable to realise their privileged position, the interpersonal relationships may suffer particularly through different interpretations of a particular encounter. Northern partners, as well as those in privileged positions in Southern contexts, find it difficult to see and understand how certain practices, ways of relating and engaging, may be experienced as controlling, manipulative or exploitative.

On the other hand, narrators also point out that issues of inequality do not only operate at the North-South axis but also between different members of the team within the same country and indeed across multiple axes of power. Thus, a PhD or postdoctoral candidate and a non-tenured researcher are clearly located differently and therefore hold different power and sway with respect to decisions than a tenured professor, as described by these two narrators:

It is not a relevant issue just between teams in the two countries, but inside the teams. There are also the cultural aspects, which are important when considering the power relations.

Broadly, the challenges may have to do with inequalities around funding; may have to do with the amount of funding contributed by different research academies or foundations, the Academy of Finland in this case contributing more money to the international collaboration than the South African National Research Foundation. They may due to different personalities, identities, ages, genders, sexualities, cultures, races, and of course nationalities of the individuals that make up the project. Or they may have to do with global North versus South histories and inequalities and how in turn they inform the assumptions and power dynamics that can get to influence, usually subtly but sometimes more directly, the character of the transnational collaboration and its success 
or failure. Power is part of the factors that constrain and challenge working transnationally; power in one or several ways. Project members and leaders are not always aware of that and need to be.

Notions of cultural difference were also raised as impacting on communication and possibly leading to misunderstandings and problematic relations:

Further constraints include a lack of cultural understanding which speaks to the point made earlier about imposing ideas. In this case, when scholars/researchers of one nationality collaborate with those of another, there is the possibility of misunderstanding and misinterpretation of cultural meanings of the lives of men, masculinities and gender justice.

The dominance of certain languages, in particular English which served as the mode of communication in the team (even though a minority of members are home English speaking), was raised as a constraint in such projects, also reinforcing existing power relations in the team:

Language is a vital theme in the collaboration. English was used for (collaborative and other) writing and talking. In both teams there were people whose mother tongue was English and people whose mother tongue was some other language. The words/concepts used are easily understood differently between and inside the research teams. Power positions were partially created based on language.

At a more material level, as already noted, the large geographical distances between the researchers was also viewed as a challenge for communication and progress:

The geographical distance in some cases also makes it difficult for important matters that would otherwise require face-to-face engagement to happen.

Finally, another key concern raised by many participants related also to historical and continued global inequalities but has more to do with the realm of ideas and knowledge than with the functioning and interpersonal dynamics of the team. In this respect, participants raised concerns about how certain theories, ideas and models may dominate in the scholarship conducted in transnational projects. Thus, a strong thread in many responses is that of concerns about the kneejerk idealisation of the global North with respect to gender justice and the flipside of the demonisation and 'othering' of the global South, as articulated by these different narrators:

A challenge related to working transnationally relates to the issue of setting up a particular place as 'the example' - of all of the ills associated with gender injustice. As researchers we ourselves are sometimes implicated in setting up binaries between contexts which are 'gender equal' and 'progressive', where injustices and violences are silenced - and those which are models of inequality, violence and associated problems. This, I think is a constant challenge when working transnationally as the focus often tends to shift toward the 'problem' - even when that isn't the explicit intention. Our problems are different, and the solutions are different so it is difficult sometimes in 
thinking through how we might work together transnationally toward the broader goals of gender justice. (Our emphasis)

The constraints and challenges of working transnationally involve among others, the urge for some nationalities to impose ideas of what the world should be like for men, how masculinities should be constructed, as well as what gender justice should look like, which hinders the process of learning from each other. (Our emphasis)

Constraints of working transnationally on young men, masculinities and gender justice may also relate to a dominance of western perspectives with the flip side being the repression of Southern knowledge in this field - thus we work in a multiplicity of contexts and yet there is a tendency to attempt to provide unitary accounts and interpret what happens in the south through northern frameworks, even we reject this and it is difficult for all of us to avoid using conceptual frameworks and lenses that are based on northern contexts even when we have the appropriate rhetoric to challenge this tendency. Thus, much of the work in Southern contexts has assumed concepts developed elsewhere, which while helpful may also have stifled a more localised understanding of the dynamics, complexities, nuances of masculinities and men in a particular context. (Our emphasis)

Linked to this concern was the way in which North-South collaborations may end up repeating this kind of 'othering' by an inadvertent overfocus on the Southern country and an underfocus on the Northern country. Thus, one narrator pointed out that structurally the teams set up facilitated this process, since there were far more South African researchers than Finnish researchers active on the team and that one way of subverting this tendency and its implications is to ensure that more research and sharing of the Northern country is included:

In the project there were 7-8 researchers (depending on how you count) studying the South African situation (the whole South African team) and three researchers from Finland, but not all were actively doing (empirical) research on the Finnish situation. There was discussion on how easily people from the North/West concentrate on South Africa, but not the other way around. It would have been easier in this project to do it other way around if there were more researchers analyzing Finnish youth and gender/sexualities, and if there was more interest in understanding how things are in Finland. Now Finland was positioned as representative of West/North (which it is), but the particularities of Finnish society and culture were not dealt that much.

\section{'Lessons' for transnational research projects}

A consistent point made by respondents in thinking about how to avoid the challenges raised for transnational collaboration is that the team needs to be clear on their reasons for working together and the goals of the project in driving their intention to work together in the first place. Ironically, this is not always possible, as often researchers in particular contexts have their collaborative relationships shaped by the kinds of funds on offer. This also explains why South-South collaborations are so difficult to achieve, since mostly the funds are located in Northern contexts and in some cases make the former possible only through the involvement of a Northern partner. The first narrator below argues for the 
importance of first establishing why a particular collaboration would be beneficial before embarking on the process. Such a process as articulated in the second and third narrative is a complex and engaged preparatory project that requires dialogue and critical reflection before the start:

My recommendation is simple, we need to establish clearly why such collaborations are necessary particularly at the level of the issues we need to address (i.e. men, masculinities and gender justice) which could also explain why certain countries/nations are chosen over others for collaborations. What it is about the one nation that we can learn or draw on when working with issues on men, masculinities and gender justice; and how would such collaboration benefit our nation, are some of the questions that need to be answered before transnational work is considered as an option for any particular project. (Author's emphasis)

I think extreme thoughtfulness and self-reflexivity at all point of the process, and possibly talk about some of these challenges or possible issues that may emerge at the outset. Perhaps even set ground rules for how we work together.

I would suggest a careful thinking through about what the trans-project is intended to do ... this thinking through has to happen in relation to the bodies that will 'occupy' the project, their modes of engagement, and areas of interests. Beyond dialogue, and joint writing projects - a careful thinking through - which might itself take the form of a dialogue needs to happen before embarking trans-projects.

Respondents also suggest that this practice of reflexivity and dialogue should be built into the process of the project, to continue throughout its life. The narrator flags the challenges of all group work and also how much of our work in academia is shaped by a masculinist institutional framework where there is little attention to the 'personal', bodily and affective realms:

Also it is important to attempt to challenge and name issues as they emerge and it is helpful to reflect on these as we are doing in this exercise. There is no one model for working together: we all have challenges working across difference and historical inequalities in our own contexts as well as within the framework of north-south historical inequalities, so there are multiple layers of difference and possible exclusionary or abusive practices in our workings with each other. Academics tend to find it easier to critique 'others' and struggle to focus on the way in which in which they are implicated in power relations, and even feminist researchers who are attuned to issues of power and subjectivity, tend to subscribe to the academic binaries and a cartesian neglect of the body and affect.

Such a thinking through is important, respondents suggest, not only for clarifying the goals and contexts of the project but also for ensuring that you are working with appropriate co-researchers. The narrator below suggests careful choice of who you work with and draws attention to multiple levels of 'appropriateness' including political, ideological, philosophical and more subjective resonance: 
I would choose who you work with very carefully indeed, and check that you are able to work with each other productively; this is a lot about trust, really trusting people. I would also check that the budget is realistic. It is also important to be reasonably close in approach, not necessarily agreeing with everything between each other, but rather respecting others' positions. I would seek to work with people who actually do things and deliver ... and perhaps most important who are interested in what happens in and between different parts of the world, transnationally, and not just for themselves, for example, those who are primarily careerist, dominating, manipulating or narcissistic ... and anti-feminist.

Respondents also draw attention to the importance of applying a critical lens on the dynamics of north-south collaboration within global contexts of inequality and privilege, right from the start - this may involve having a discussion about this and/or engaging a particular theoretical lens that may make sure such global dynamics are made visible to the researchers before they begin working together:

Maybe the project could start the whole cooperation with discussing the fact that most north- south collaborations are in the north funded by development aid money, and the implications of that.

Maybe to read postcolonial feminist theory and critical race and whiteness studies.

Similarly, respondents who raised concerns with cultural differences as a constraint in transnational projects suggested the importance of long-term working relationships for working on possible misunderstandings that may inhibit the project progress:

In such cases, the groups involved would need to have a longer-term working relationship to ensure that they all understand the different meanings involved for each nation and whether the priorities are the same and can actually feed-off or engage each other within the different contexts.

Others draw attention to the more interpersonal and psycho-social context of such collaborations, including a focus on the emotional labour involved in ensuring that the group facilitates a constructive and caring framework. In calling for attention to the process, not only the outputs, respondents speak of the importance of building relationship, trust and 'negotiating emotions' as in these three narratives below:

Trust between people is vital, and it does not come automatically, but needs to be worked at. Be interested in other people and their work.

It can be challenging working in such projects. It can be exhausting, and you may even experience some falling out at some points. You know, it's become very clear that working with others involves emotional labour as it does doing presentations and sending emails and discussion literature, theories, approaches, methods, findings, and conclusions. Working transnationally might mean learning about and negotiating emotions across national borders. Still, you can never be as prepared for the emotional matters as you can be for the technical stuff. (Our emphasis) 
Doing activities outside the formal meetings seems to help in finding each other and learning about each other. Activities like eating together or taking a day out to learn about each other's nations or culture are useful.

The project of focusing on the more subjective and interpersonal also requires ensuring the clarification of personal goals and objectives within the larger project imperatives:

You have to find each other as a group or individuals in such projects. It can be done. But it can take time. If you are fortunate, it can be done in one or two meetings set aside to clarify how to work transnationally. But the bottom line is you have to learn from where each of you is coming. So do make time to clarify expectations and hopes and individuals' goals, over and above the stated objectives of the project.

Other 'lessons' raised relate to the concerns emerging from some narrators, that the collaborative work may serve to reproduce certain problematic discourses and representations, such as what Grewal (2013) has called the 'outsourcing of patriarchy' or what Puar, Grewal, Kaplan, and Wiegman (2007) calls 'homonationalism' with respect to homophobia, the setting up of the global Northern nation-state as engaged in a 'civilising' mission:

It seems very important for transnational projects on men and masculinities and gender and other forms of oppression to reflect on how they present [their research] - events across two contexts should not end up focusing only on the South African or African experiences as tends to happen. Although this gain is one associated with some discomfort, it is a valuable outcome of working transnationally.

Another suggestion offered by respondents is that it is important for the project members to engage and dialogue with a wider pool of researchers and members of civil society in the different countries than only their co-researchers:

Bringing others who are not directly connected to your specific project to give other perspectives about the 'nation' or society may be of help. It means the participants in the project from the different countries hear more than one story from the different countries involved and gives a bigger context for your transnational work.

Finally, some respondents also pointed to the more material tasks of constructive team work, always a challenge but perhaps complicated by the geographical distances of transnational projects:

Plan carefully beforehand what is going to happen, decide who is responsible for various tasks and how money issues will be handled. Keep an update on what has been decided, and share all the relevant information with others in the teams. Democratic decision making and listening to all viewpoints is important.

To put it simply, transnational projects have to be done. 


\section{Concluding thoughts}

This dialogue, or more precisely metalogue, has highlighted many issues and possibilities: some more practical, some more theoretical, some directed at our concerns with young men, masculinities and gender justice, some of a more generic nature. If nothing else, a transnational research project such as this provides fertile ground for reflection and growth for all researchers on the team, especially if self-reflective exercises, including the one on which this article is based, are included. However, even these processes of dialogue and reflection or reflexivity are themselves for from neutral activities. They raise questions of how to organise even this dialogue in an appropriate and democratic way, how to select themes and quotations from the rather extensive responses and to present these individual and collective experiences and reflections in an accurate way. Indeed, we can ask directly, what is to count as dialogue in the general, and in the specific? What different kinds of dialogue, and metalogue, are there - how does this differ from clear (Habermasian) communicative competences on one plane or transversal politics (see, for example, Cockburn, 1998; Cockburn \& Hunter, 1999; Yuval-Davis, 1997) on another. Furthermore, the very notion of reflexivity, while necessary, is not sufficient for gender justice and anti-oppressive movement; it is itself variable, complex and contingent, no guarantee of anything; there are no doubt many reflexive fascists.

Finally, the combination of, first, transnational, in this case North-South, research, second, reflective dialogue, and, third, our focus here on young men, masculinities and gender justice presents some larger scale challenges in terms of the construction of knowledges. This framing becomes destabilised, not disconnected from time and place and their intersections. There is not just concern with the production of knowledges in the 'North', 'South' (Connell, 2008, 2014), 'metropole', 'periphery' and 'semi-periphery' (Blagojević, 2009) and so on, but intersections between and across those places and times, and indeed between those betweennesses and crossings. Likewise, young men, masculinities and gender justice(s) are remaining contested, unfinished and problematic.

\section{Acknowledgements}

Thanks to all the collaborative research team members who contributed so generously their reflections that are drawn on here including: Floretta Boonzaier, Mbuyiselo Botha, Jeff Hearn, Melanie Judge, Katarina Jungar, Jukka Lehtonen, Mandisa Malinga, Trevor McArthur, Rob Pattman, Kopano Ratele and Tamara Shefer. Also thanks to Brittany Everitt-Penhale for kind administrative assistance.

\section{Funding}

This article results from a 3-year collaborative transnational research project 'Engaging South African and Finnish youth towards new traditions of non-violence, equality and social well-being', funded by the National Research Foundation (NRF) of South Africa, and the Academy of Finland.

\section{Disclosure statement}

No potential conflict of interest was reported by the authors 


\section{Notes}

1. See Acknowledgements for the list of those invited to contribute to this dialogue.

2. These were: 'What are the gains, possibilities and value of working transnationally on young men, masculinities and gender justice?' 'What are the constraints and challenges of working transnationally on young men, masculinities and gender justice?' 'What lessons would you advance about working transnationally, i.e. what would you recommend to others who wish to engage in a transnational project to do and/or not to do in working together across borders/nations/continents?'

3. We have corrected typing errors as well as language errors made as a result of writing in a language that is not the respondent's first language. Italics indicate emphasis. Different narrators are indicated by a line break.

4. Paradoxically, exceptionalism is a very widespread socio-political phenomenon to be found in both large powerful countries, most obviously 'American [i.e. US] exceptionalism', and in local, even village communities, each as being unique in history, character and form. Postcolonial exceptionalism is especially interesting for our purposes, in relation to both Finland (between

'East' and 'West Europe', between Russia and Sweden) and South Africa (with its particular, if not unique, history of apartheid that in time attracted major international attention, for example, through various boycotts, including those in academia and sport).

5. In South Africa, universities were created and divided on the basis of race and language/ ethnicity. Universities for whites, who were a minority, were numerous and received the bulk of higher education budget, while universities for blacks were underfunded and overcrowded, with some ethnic universities located in what were called 'black homelands'. While legislated discrimination has been scrapped in postapartheid society, the structures and legacies of colonial and apartheid discrimination endure.

6. The Finnish budget funded two Finnish postdoctoral project researchers for most of the project, three South African doctoral students for one year each, travel to South Africa, and meetings and hosting in Finland. This was much larger than the South African budget, which funded travel to Finland and meetings and hosting in South Africa. Some other limited funds were accessed in both countries.

\section{Notes on contributors}

Tamara Shefer is Professor of Women's and Gender Studies and Deputy Dean of Teaching and Learning in the Faculty of Arts at the University of the Western Cape. Her scholarship is mostly in the areas of youth, gender and sexualities, including a focus on HIV/AIDS, gender-based violence, masculinities, memory and post-apartheid, gender and care, and social justice in higher education.

Jeff Hearn is Professor of Management and Organisation, Hanken School of Economics, Finland; Guest Research Professor in the Faculty of Humanities and Social Sciences, based in the Centre for Feminist Social Studies, Örebro University, Sweden; and Professor of Sociology, University of Huddersfield, UK: His latest book is Men of the World: Genders, Globalization, Transnational Times, Sage, 2015.

Kopano Ratele is Professor in the Institute for Social and Health Sciences at the University of South Africa (Unisa) and Researcher at the South African Medical Research Council- 
Unisa's Violence, Injury \& Peace Research Unit. He is past president of the Psychological Society of South Africa and chairperson of the board of Sonke Gender Justice. He writes on masculinity in relation to violence, tradition, culture, race and sexuality. 


\section{References}

Academy of Finland. (2012). Children and youth (academy and NRF, South Africa). Retrieved from http://www.aka.fi/en-GB/A/Funding-and-guidance/Funding/AZindex/Children-and-Youth/

Airhihenbuwa, C. O., Shisana, O., Zungu, N., Belue, R., Makofani, D. M., Shefer, T., Smith, E., \& Simbayi, L. (2011). Research capacity building: A US-South African partnership. Global Health Promotion, 18(2), 27-35. doi:10.1177/1757975911404745

Blagojević, M. (2009). Knowledge production at the semiperiphery: A gender perspective. Belgrade: Institut za kriminolośka I sosiolośka istraźivanja.

Carabí, A., and Armengol, J. M. (Eds.). (2014). Alternative masculinities for a changing world. New York: Palgrave Macmillan.

Cockburn, C. K. (1998). The space between us: Negotiating gender and national identities in conflict. London: Zed.

Cockburn, C. K., \& Hunter, L. (Eds.). (1999). Soundings: Issue 12 - Transversal politics. London: Lawrence and Whishart.

Connell, R. W. (1993). The big picture: Masculinities in recent world history. Theory and Society, 22, 597-623. doi:10.1007/BFoo993538

Connell, R. (2000). The men and the boys. Cambridge: Polity. Connell, R. (2008). Southern theory. Cambridge: Polity.

Connell, R. W. (2014). Margin becoming centre: For a world-centred rethinking of masculinities. NORMA: International Journal for Masculinity Studies, 9(4), 217-231. doi:10.1080/18902138.2014.934078

Cornwall, A., Edström, J., \& Greig, A. (Eds.). (2011). Men and development: Politicising masculinities. London: Zed.

Gelfer, J. (Ed.). (2013). Masculinities in a global era. Berlin: Springer.

Grewal, I. (2013). Outsourcing patriarchy: Feminist encounters, transnational mediations and the crime of 'honour killings'. International Feminist Journal of Politics, 15(1), 1-19. doi:10.1080/14616742.2012.755352

Hearn, J. (1996). Deconstructing the dominant: Making the one(s) the other(s). Organization: The Interdisciplinary Journal of Organization, Theory and Society, 3, 611-626.

Hearn, J. (2014). International studies on men, masculinities and gender equality. Men and Masculinities, 17, 455-466. doi:10.1177/1097184X14558232

Hearn, J. (2015a). Men of the world: Genders, globalizations, transnational times. London: Sage.

Hearn, J. (2015b). Transnational reflections on transnational research projects on men, boys and gender relations. NORMA: International Journal for Masculinity Studies, 10. doi:10.1080/18902138.2015.105058

Hearn, J., Blagojević, M., \& Harrison, K. (Eds.). (2013). Rethinking transnational men: Beyond, between and within nations. New York: Routledge.

Hearn, J., \& Morrell, R. (2012). Reviewing hegemonic masculinities and men in Sweden and South Africa: An introduction. Men and Masculinities, 15(1), 3-10. doi:10.1177/1097184X12438001

Hearn, J., \& Pringle, K., with members of Critical Research on Men in Europe. (2006). European perspectives on men and masculinities: National and transnational approaches. Houndmills: Palgrave Macmillan. doi:10.1057/9780230626447 
Hearn, J., Nordberg, M., Andersson, K., Balkmar, D., Gottzén, L., Klinth, R., Pringle, K., \& Sandberg, L. (2012). Hegemonic masculinity and beyond: 40 years of research in Sweden. Men and Masculinities, 15(1), 31-55. doi:10.1177/1097184X11432113

Morrell, R., Jewkes, R., \& Lindegger, G. (2012). Hegemonic masculinity/ies in South Africa: Culture, power and gender politics. Men and Masculinities, 15(1), 11-30. doi:10.1177/1097184X12438001

Pease, B., \& Pringle, K. (Eds.). (2002). A man's world: Changing men's practices in a globalized world. London: Zed.

Pringle, K., Hearn, J., Ferguson, H., Kambourov, D., Kolga, V., Lattu, E., ... Niemi, H. (2006/2013). Men and masculinities in Europe. London: Whiting \& Birch.

Puar, J. K., Grewal, I., Kaplan, C., \& Wiegman, R. (2007). Terrorist assemblages: Homonationalism in queer times. Durham, NC: Duke University Press. doi:10.1215/9780822390442

Ratele, K. (2014). Currents against gender transformation of South African men: Relocating marginality to the centre of research and theory of masculinities. NORMA: Nordic Journal For Masculinity Studies, 9(1), 30-44. doi:10.1080/18902138.2014.892285

Reddy, V., Meyer, S., Shefer, T., \& Meyiwa, T. (Eds.). (2014). Care in context: Transnational gender perspectives. Pretoria: HSRC Press.

Ruspini, E., Hearn, J., Pease, B., \& Pringle, K. (Eds.). (2011). Men and masculinities around the world: Transforming men's practices. New York: Palgrave Macmillan.

van der Gaag, N. (2014). Feminism \& men. London: Zed. (1997). Gender and nation. London: Sage. 